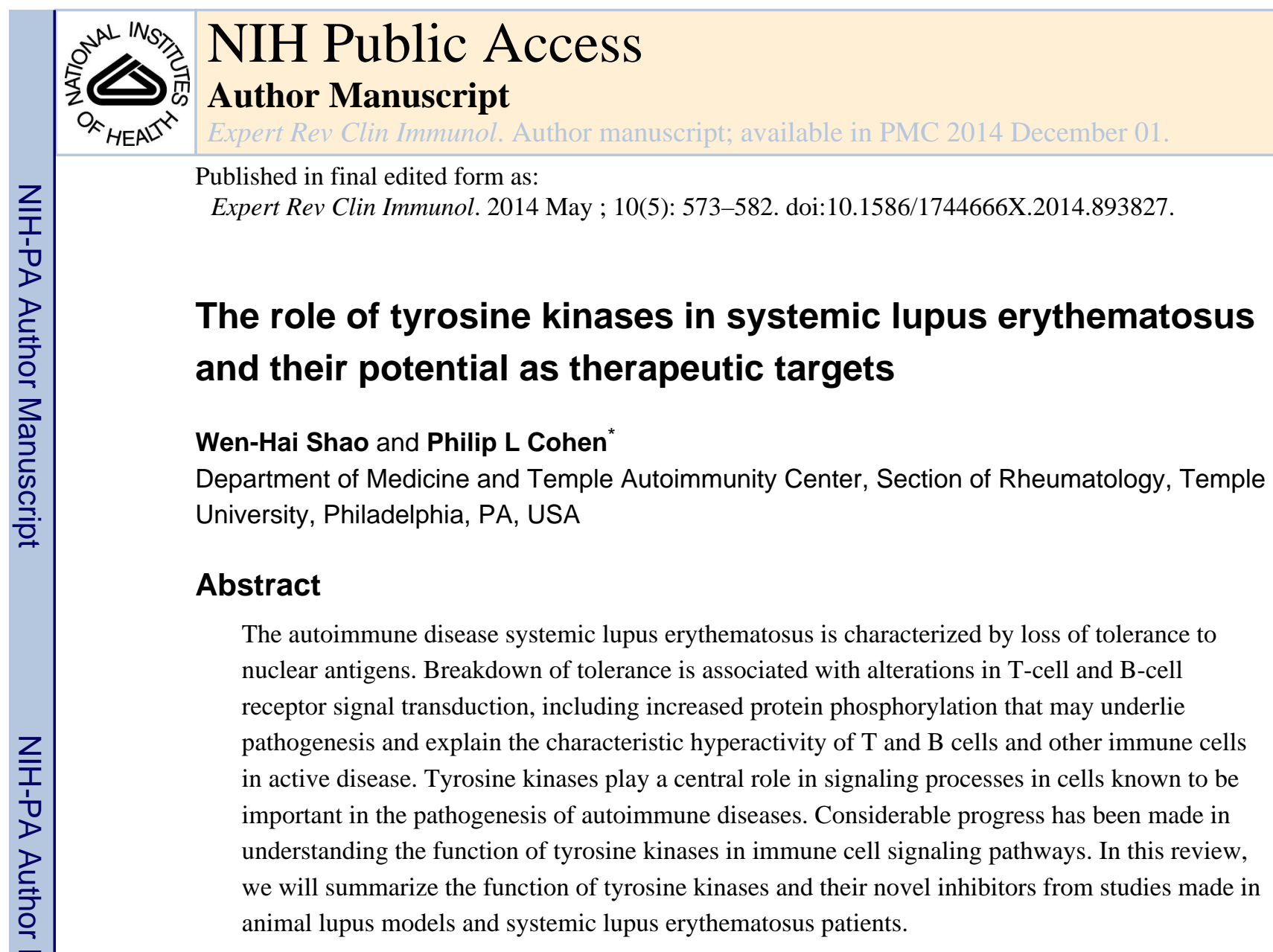

\title{
Keywords
}

apoptotic cell clearance; systemic lupus erythematosus; tyrosine kinase; tyrosine kinase inhibitor

\begin{abstract}
Systemic lupus erythematosus (SLE) is a chronic autoimmune disease, characterized by the occurrence of many different autoantibodies, the formation of immune complexes and inflammation in multiple organs. SLE patients have both increased circulating apoptotic mononuclear cells and a defective clearance of apoptotic bodies. Among the cells in the immune system, the B cells in SLE patients have multiple abnormalities that may account for the ongoing autoantibody production. In parallel, abnormal T-cell activation and production of cytokines are well known, and these may also be critical for the initiation and maintenance of the autoimmune reaction.

Members of the tyrosine kinase family have roles in the control of cell survival, activation and differentiation. Based on their structure, tyrosine kinase families are classified either as receptor or as non-receptor kinases. Receptor tyrosine kinases share the features of typical transmembrane glycoproteins. All non-receptor tyrosine kinases share Src-homology-2
\end{abstract}

\footnotetext{
() 2014 Informa UK Ltd

*Author for correspondence: Tel.: +1 215707 5660, Fax: +1 215707 3508, philco@temple.edu.

Financial \& competing interests disclosure

The authors have no other relevant affiliations or financial involvement with any organization or entity with a financial interest in or financial conflict with the subject matter or materials discussed in the manuscript apart from those disclosed.

No writing assistance was utilized in the production of this manuscript.
} 
(SH-2) and -3 regions in the N-terminal part of the protein. Studies from animal models and SLE patients have revealed abnormalities of tyrosine kinases in T cells, B cells, plasma cells and other immune cells of the innate and adaptive immune systems. This review will discuss the etiologic and pathogenic role of tyrosine kinases in SLE and their therapeutic potential.

\section{Spleen tyrosine kinase}

Spleen tyrosine kinase (Syk) is a cytoplasmic tyrosine kinase of $72 \mathrm{kDa}$. It contains two SH-2 domains and a kinase domain. Syk is widely expressed in the hematopoietic lineage of the immune system, including B cells and T cells. Syk is a positive effector of B-cell receptor (BCR)-stimulated responses and is required for B-cell development as well as the maintenance of mature B cells [1,2]. Mice lacking Syk died at the perinatal stage [1]. Following the engagement of BCR, Syk is recruited to the site of the clustered receptor, leading to its phosphorylation/activation. Higher amounts of Syk expression and activity were detected in SLE T cells compared with controls [3]. T-cell receptor (TCR) signaling in SLE T cells is reported to be modified by an alternative pathway involving Fc receptor $\gamma$ signaling chain $(\mathrm{FcR} \gamma)$ and Syk. $\mathrm{FcR} \gamma$ is homologous in shape and function to $\mathrm{CD} 3 \zeta$, and binding between Syk and FcR $\gamma$ was observed in SLE but not in normal T cells. In addition, Syk is 100-fold more potent compared with zeta-chain-associated protein kinase 70 (ZAP-70) in binding to the FceRI $\gamma$. When overexpressed, FceRI $\gamma$ was reported to co-localize with the $\mathrm{CD} 3 \zeta$ chain. A dramatic increase of intracytoplasmic calcium concentration, protein tyrosine phosphorylation and IL-2 production was observed in peripheral T cells transfected with FceRI $\gamma$. Increased phosphorylation of Syk kinase was found to be associated with the FceRI $\gamma$ overexpression [4]. On the other hand, silencing of Syk in SLE T cells normalized the expression of most abnormally produced molecules (IL-21, CD44 and intracellular molecules protein phosphatase $2 \mathrm{~A}$ and $2^{\prime}-5^{\prime}$-oligoadenylate synthetase 2 ), while overexpression of Syk in healthy $\mathrm{T}$ cells restored most of the aberrantly expressed molecules [5]. Syk tends to bind preferentially with Vav-1 and LAT contributing to the enhanced TCRinduced signaling responses in SLE T cells [3]. When ZAP-70 was knocked in under the intrinsic Syk promoter, it altered BCR signaling quality, resulting in preferential development and survival of marginal zone B cells and prominent autoreactivity with agerelated immune complex-mediated glomerulonephritis [6].

Syk is also being considered as a therapeutic target in SLE patients. Selective inhibition of the activity of Syk reduced the strength of TCR-induced calcium responses and slowed the rapid kinetics of actin polymerization in SLE T cells, but not in normal donor T cells [3]. R406 is an oral Syk inhibitor, shown to block IgE- and IgG-mediated activation of Fc receptors, with reduced immune complex-mediated inflammation [7]. R788 (fostamatinib) is a small-molecule, water-soluble prodrug of the biologically active R406 and a potent inhibitor of Syk. It has moderate activity in treatment of human rheumatoid arthritis (RA), and trials of its use in idiopathic thrombocytopenic purpura are underway. When R788 was administered long-term (24-34 weeks) to lupus-prone NZB/NZW mice before and after disease onset, it delayed the onset of proteinuria, reduced renal pathology and kidney infiltrates and significantly prolonged survival in these mice. A dose-dependent reduction in the numbers of $\mathrm{CD} 4^{+}$-activated $\mathrm{T}$ cells $\left(\mathrm{CD} 44^{\mathrm{hi}}\right.$ or $\left.\mathrm{CD} 69^{\text {hi }}\right)$ was noted in spleens from $\mathrm{R} 788$ treated mice [8]. Treatment of lupus-prone MRL/lpr and BAX/BAK mice with R788 not 
only prevented the development of skin and renal pathology but also treated established disease. Upon discontinuation of the treatment, there was extended suppression of skin (8 weeks) and renal disease (4 weeks) [9]. An early Phase II clinical trial involving 189 RA patients showed significant improvement in ACR20, 50, 70 and Disease Activity Score 28 [10]. However, the recent Phase II, 3-month randomized, placebo-controlled study in patients with active RA reported no significant differences between the R788 and placebo groups [11]. Moreover, AstraZeneca has decided not to proceed with fostamatinib based on the Phase III program.

\section{Bruton's tyrosine kinase}

Bruton's tyrosine kinase (Btk) is a member of the Tec family of tyrosine kinases. It contains an N-terminal pleckstrin homology domain, followed by a Tec homology and SH-3, -2, -1 (catalytic) domains. Btk is a BCR signaling molecule that affects B-cell development, selection, activation and survival [12]. Mutations in Btk are responsible for Bruton's Xlinked agammaglobulinemia in humans, which is characterized by severe defects in early Bcell development with a near-complete absence of peripheral B cells and immunoglobulin of all classes. In mice, Btk mutations cause a phenotypically milder X-linked immunodeficiency [13]. Transgenic mice overexpressing Btk specifically in B cells spontaneously form germinal centers and have increased plasma cell numbers, with antinuclear autoantibody production and SLE-like autoimmune pathology affecting kidneys, lungs and salivary glands [14]. Halcomb et al. generated $\mathrm{Btk}^{-/-}$mice on the B6.56R background carrying a high-affinity anti-DNA IgH transgene. dsDNA-specific B cells were present in the B6.56R.Btk ${ }^{-1}$ mice, but anti-dsDNA was not detected in the serum. Reintroduction of Btk expression at low levels $\left(\mathrm{Btk}^{\mathrm{lo}}\right)$ in the B6.56R mice restored anti-DNA IgM but not anti-DNA IgG. Overexpression of Btk had no effect on anti-dsDNA IgG levels in B6.56R mice [15].

Btk levels set the threshold for mouse autoreactive B-cell activation and negative selection [14]. Btk is also required for both Toll-like receptor (TLR)9 and BCR signal transduction. In response to crosslinking of the $\mathrm{BCR}$, Btk is recruited to the plasma membrane via its pleckstrin homology domain and becomes activated. It then phosphorylates phospholipase $\mathrm{C}-\gamma 2$, which in turn, cleaves phosphatidylinositol 4,5-bisphosphate into diacylglycerol and inositol trisphosphate. Generation of inositol trisphosphate leads to the release of calcium. Increased cytosolic $\mathrm{Ca}^{2+}$ in response to $\mathrm{BCR}$ stimulation ensures the full activation of $\mathrm{B}$ cells (Figure 1). Overexpressing of Btk in B cells leads to selective hyper-responsiveness to BCR stimulation with enhanced $\mathrm{Ca}^{2+}$ influx. In primary murine $\mathrm{B}$ cells, TLR9 synergizes with BCR, leading to an enhanced signal transduction through an auto-phagosome-like compartment upon BCR activation. Btk is required for co-localization of the BCR and TLR9 within the primary auto-phagosome-like compartment in the Namalwa human B cell line. Btk functions in this process via its effect on calcium flux [16].

A seemingly opposite function for Btk in the pathogenesis of autoimmunity was reported by Byrne et al. [17]. The molecular chaperone calreticulin regulates uptake of C1q-opsonized apoptotic cells by binding to the transmembrane receptor CD91. Btk-mediated phosphorylation of calreticulin is necessary for its co-localization with CD91. Bone marrow- 
derived macrophages generated from $\mathrm{Btk}^{-/-}$mice showed reduced phagocytic uptake of apoptotic neutrophils. Human monocytes treated with LFM-A13 (dual Btk/Polo-like kinases inhibitor) displayed a significant reduction in clearance of apoptotic cells by monocytes in comparison with vehicle-treated cells [17]. Moreover, X-linked agammaglobulinemia patients have been demonstrated to have reduced $\mathrm{Fc} \gamma$ - and complement-mediated phagocytosis [18].

Btk has been shown to be an important target in B-cell activation in autoimmune diseases. Over the last few years, considerable efforts have been made in order to develop smallmolecule inhibitors for Btk [19,20]. Ibrutinib (PCI-32765) is a selective and irreversible Btk inhibitor that inhibits BCR signaling in human B cells. Ibrutinib inactivates Btk through covalent binding to the active site of Btk [21]. In an in vitro study utilizing ibrutinib, Kenny et al. found that Btk is essential for TLR9 and BCR synergy from an auto-phagosome-like compartment. Ibrutinib treatment of SLE-like Btk transgenic mice normalized B-cell activation and differentiation [14]. B6. sle1 mice supplied with $0.16 \mathrm{mg} / \mathrm{ml}$ of ibrutinib in drinking water showed dampened humoral autoimmunity. More important, the same dose of ibrutinib given to B6.sle1. sle3 bicongenic mice delayed autoantibody production, reduced leukocyte activation and alleviated renal damage [22]. RN486, a potent competitive small molecule with reversible Btk-inhibitory property, blocks BCR-mediated CD69 expression in $B$ cells in a dose-dependent manner. When given to NZB/NZW mice in chow at a final concentration of $30 \mathrm{mg} / \mathrm{kg}$ for 8 weeks at 32 weeks of age, RN486 completely stopped progression of glomerulonephritis. RN486 induced marked reduction of anti-dsDNA and caused depletion of CD138 ${ }^{\text {hi }}$ B220lo plasma cells [23]. Trials of ibrutinib in SLE patients have considerable potential, although Btk has not been shown to be involved in the pathophysiology of human SLE (Figure 1).

\section{Tyrosine kinase 2}

Tyrosine kinase 2 (Tyk2), a key component of the type I IFN (IFN-I) signaling pathway, is part of the Janus kinase that binds to the IFN-a receptor, IFNAR. Binding of IFN-a to IFNAR allows the activation of Tyk2, which then phosphorylates IFNAR to allow binding of IRF3 and IRF5. The production of IFN-I and the regulation of IFN-inducible genes have crucial importance in SLE susceptibility, disease activity and severity. Polymorphisms of $T y k 2$ have been shown to be associated with SLE. Graham $e$ al. studied the Tyk2 polymorphisms in 380 UK SLE families, consisting of parents and affected offspring, and found two associated haplotypes across Tyk2, both carrying alleles with distorted inheritance (tags for undertransmitted and over-transmitted haplotypes, respectively) [24]. Jarvinen et al. recruited 219 Finnish patients with discoid lupus erythematosus or subacute cutaneous lupus erythematosus and 365 healthy controls. Risk genes were tagged by SNP. Tyk2 rs2304256 was reported to be associated with increased risk of discoid lupus erythematosus [25]. In another study of 44 SNPs involving 679 SLE patients from Sweden, Finland and Iceland, 798 unaffected family members and 438 unrelated control individuals, Tyk2 was strongly associated with IRF5 in SLE patients (unadjusted $\mathrm{p}<10^{-7}$ ) [26]. Hellquist et al. also reported a significant association between Tyk2 (rs2304256 and rs12720270) and IRF5 (rs1095213) by an SNP study involving 277 Finnish SLE patients and 356 healthy controls [27]. However, Gonzalez and collaborators claimed no statistical 
evidence of interaction between SLE-associated SNPs in Tyk2 and TRF5 from data with threefold more samples (1223 cases and 1300 controls) in a letter to the editor of the same journal that published the study by Hellquist et al [28]. Li et al. commented on the study by Hellquist et al., with data showing no association of Tyk2 gene polymorphisms in Chinese patients with SLE [29], which was further supported by a study of $T y k 2$ polymorphisms in SLE-susceptible genetic risk factors in a Japanese population [30]. Nevertheless, a metaanalysis by Lee $e t$ al. revealed an association of the rs6445975 polymorphism of phox homology domain containing serine/threonine kinase and the rs2304256 polymorphism of Tyk2 with the development of SLE in Europeans, but not in Asians [31]. Taken together, there is clearly an ethnic difference in $T y k 2$ polymorphisms in association with SLE susceptibility genes.

\section{Src family protein tyrosine kinases}

The Src family of non-receptor protein tyrosine kinases comprises Lyn, Src, Yes, Fgr, Fyn, LSTRA cell kinase (Lck), Hck, B-lymphoid kinase (Blk), Yrk et al. The level of Src family tyrosine kinase activity is an important determinant of immune tolerance. Several studies suggest that there is a significant interaction between Src family tyrosine kinases and the Fas pathway that is important for self-tolerance.

Lyn is predominantly expressed in all blood mononuclear cells except $\mathrm{T}$ cells, and associates with a number of cell surface receptors including BCR and FceRI. Lyn is a critical negative regulator of B-cell activation. $\mathrm{Lyn}^{-/-} \mathrm{B}$ cells were found to be both hyperresponsive to BCR ligation and resistant to the inhibitory consequence of co-ligating Fc $\gamma$ RIIb1 or CD22 with BCR [32]. B cells with disrupted Lyn expression have a delayed but increased calcium flux and exaggerated negative selection responses in the presence of antigen, and spontaneous hyperactivity in the absence of antigen [33]. Aged $\mathrm{Lyn}^{-1-}$ mice developed pathologic features of SLE, accompanied by autoantibodies in their serum and the deposition of immune complexes in their kidneys [34,35]. Recently, the dendritic cell (DC)-specific deletion of Lyn (lynfff $\mathrm{Cdl} 1 \mathrm{c}$-cre ${ }^{+}$) was generated by Lamagna et al. using the Cre-loxP system [36]. Lyn-deficient DCs were hyperactivated and hyperresponsive in response to LPS and IL-1 $\beta$ stimulation. Mice with Lyn-deficient DCs developed spontaneous B- and Tcell activation and subsequent production of autoantibodies and severe nephritis.

Interestingly, deletion of MyD88 in DCs lacking Lyn completely reversed the inflammatory autoimmunity in the DC-specific Lyn-mutant mice [36]. Surprisingly, mice targeted with gain-of-function of Lyn (Lyn ${ }^{\text {up/up }}$ mice) displayed inhibitory B-cell signaling, but eventually enhanced positive signaling that overrode the constitutive negative signaling, causing $\mathrm{Lyn}^{\text {up/up }}$ mice to develop circulating autoantibodies and lethal autoimmune glomerulonephritis [37]. Eight to tenfold increased numbers of B1a cells were found in the peritoneal cavities of $\mathrm{Lyn}^{\text {up/up }}$ mice and were associated with increased IgM levels. As B1a B cells have been implicated in the pathogenesis of SLE, autoimmunity in Lyn ${ }^{\text {up/up }}$ mice may be a result of their elevated numbers of B1 cells. Expression of Lyn was significantly decreased in resting B-cell lysates obtained from $66 \%$ of patients with SLE, but not from disease-control patients and healthy volunteers. The deficiency in protein expression was caused at least partially by defects at the transcriptional level, since mRNA levels were also reported to significantly decrease in the same patient cohort [38]. Lu et al. targeted Lyn with 
SNP in case-control association studies involving a cohort of European-American, AfricanAmerican and Korean SLE subjects. A significant association with Lyn rs6983130 was revealed in a female-only analysis from the combined European-derived population, consisting of 2463 independent cases and 3131 unrelated controls [39]. Multivariate logistic regression analysis implicated rs6983130 as a protective factor for SLE susceptibility when anti-dsDNA, anti-chromatin, anti-52 kDa Ro or anti-Sm autoantibody status were used as covariates [39]. However, out of 90 SNPs tested in the study, none of them showed significant association with SLE in the African-American or Korean populations.

Lck, a $56 \mathrm{kDa}$ Src family tyrosine kinase, is critical for T-cell development and activation. Lck associates with the cytoplasmic tails of the CD4 or CD8. Intracellular status of Lck determines the specificity of thymic selection, and thymic selection of MHC-restricted TCR is Lck-dependent [40]. Lck was found to phosphorylate and regulate the cell surface expression of cytotoxic T lymphocyte-associated molecule-4, signaling through which regulates T-cell activation [41]. Though a relatively small cohort of patients was studied, Lck was reported to be significantly reduced in peripheral blood $\mathrm{T}$ lymphocytes from patients with active SLE compared with healthy controls and RA patients [42]. Similar observations were made by a Romanian group [43], which reported lower Lck mRNA and p56Lck protein in SLE patients. They found an inverse correlation between expression of p56Lck and apoptosis of fresh and cultured SLE peripheral blood T lymphocytes. In the absence of Lck, T cells required considerably higher doses of antigen to achieve the threshold required to enter into cell division. Lck-mediated signals are required for differentiation of naïve T cells [44]. Since Lck kinase activity is critical for TCR-mediated signaling in T-cell activation and its expression is restricted to lymphoid cells, an Lckselective inhibitor would be expected to have a significantly improved safety profile for the treatment of SLE.

Fyn is associated with the $\mathrm{CD} 3 \zeta$ chain and, along with Lck, participates in TCR-mediated proximal signal transduction. Elevated levels of p59fyn mRNA were found to be threefold greater in $\operatorname{lpr} \mathrm{CD} 4 \mathrm{CD} 8$ double-negative T cells [45]. Fyn was found to transduce activation signals to the double-negative T cells in MRL/lpr mice [46]. Significantly higher mRNA levels of Fyn were also observed in SLE CD4 ${ }^{+} \mathrm{T}$ cells than in healthy individuals [47]. Mice deficient in both Lyn and Fyn died at relatively young ages and developed a severe lupuslike kidney disease, which mostly resembles the findings seen in Lyn single knockout mice. Fyn deficiency predisposes the glomeruli to damage resulting from immune complex deposition (caused by Lyn deficiency) through kidney-intrinsic defects [48]. Issues regarding the kidney-intrinsic defects are not well elucidated yet.

Blk is involved in B-cell development, differentiation and signaling. Blk-mediated signaling plays an important role in transmitting signals through BCR, and for growth arrest and apoptosis. Blk also contributes to Btk activation by indirectly stimulating Btk intramolecular autophosphorylation. A multicenter study genotyped more than 500,000 SNPs in DNA samples from 1311 SLE cases and 1783 controls from North Americans of European descent. A promoter-region allele associated with reduced expression of Blk was linked to decreased risk in both the US and Swedish case-control series [49]. 
C-Src kinase (Csk) is a $50 \mathrm{kDa}$ tyrosine kinase with a kinase domain in its C-terminus. Csk is not itself a member of Src family tyrosine kinases, but serves as an indispensable negative regulator of the Src family kinases by specifically phosphorylating the conserved C-terminal negative regulatory site [50]. Homozygous Csk mutant embryos die at neurulation stages with defects in neural tube closure. $\mathrm{Csk}^{-1-}$ embryonal tissues and cell lines exhibit increased activity of all Src kinases [50]. The physical interaction between Csk and Lyp (the product of the PTPN22 gene) has been strongly associated with many autoimmune diseases [51]. A study of a cohort of 24 SLE samples showed that the Csk intronic polymorphism rs34933034 is associated with increased Csk expression and augments inhibitory phosphorylation of Lyn. Increased BCR-mediated activation of mature B cells and higher IgM were also observed in the SLE patients carrying the Csk mutation [52]. Direct interaction between Csk and Lyp is not required for TCR signaling, though the Lyp/Sck interaction is inducible upon TCR stimulation [53].

\section{Receptor tyrosine kinases}

TAM family receptor tyrosine kinases are three closely related receptors: Tyro-3, Axl and Mer. They have a defining arrangement of two immunoglobulin-like domains and two fibronectin-III repeats, followed by a catalytic cytoplasmic tail connected through a single transmembrane domain. TAM receptors are mainly expressed in cells of the immune, reproductive and vascular systems [54]. These receptors play an essential immunoregulatory role by promoting apoptotic cell clearance, maintaining immune homeostasis and providing negative regulation of TLR and cytokine receptor signaling [55,56]. Mice lacking the single receptor Mer have impaired clearance of infused apoptotic cells and develop progressive lupus-like autoimmunity [57]. TAM triple deficient mice developed a broader spectrum of autoimmune clinical manifestations, including arthritis, skin lesions, vasculitis and IgG deposition in glomeruli [58]. Autoantibodies against dsDNA and phospholipids are present. Impaired phagocytic clearance in the triple $\mathrm{TAM}^{-/}$testis leads to accumulation of dead cells, which accounts for the infertility of male mice [59]. Mer-deficient 2G7 anti-Smtransgenic mice, unlike wild-type $2 \mathrm{G} 7$ transgenics, develop an anti-Sm response beginning at 1-2 months of age. Autoreactive anti-Sm B cells originate from marginal zones and B1 B cells are activated in an Ag-specific manner [60]. The involvement of TAM receptors in human autoimmune diseases has been investigated in several studies. Mer polymorphisms were significantly associated with the risk of hematological disorders among Korean SLE patients [61]. Wu et al. studied plasma concentrations of soluble Mer (sMer, cleaved extracellular portion of Mer) and soluble Tyro-3 and reported a significant increase of both in patients with active SLE and RA [62]. An increase in all three soluble TAM receptors was also reported in plasma of SLE patients [63].

Our laboratory has long been interested in the role of TAM receptors and their ligands in the disease activity of SLE. We studied the plasma levels of TAM receptors and their ligands, growth arrest-specific protein 6 and protein S in SLE patients. In one study, we measured growth arrest-specific protein 6 and protein S levels in 107 SLE patients using ELISA and found a strong positive correlation of free protein $\mathrm{S}$ with complement $\mathrm{C} 3$ and $\mathrm{C} 4$ levels. Lower free protein S was found in SLE patients with anti-Sm or anti-cardiolipin IgG [64]. Recently, we observed an increased Mer expression on CD1c ${ }^{+}$myeloid DCs and 
plasmacytoid DCs in SLE patients compared with controls. The expression levels of Mer on $\mathrm{CD} 14^{\text {int }} \mathrm{CD} 16^{+}$monocytes and $\mathrm{CD} 1 \mathrm{c}^{+}$DCs correlated positively with IFN-I activity [65]. sMer in lupus was significantly associated with anti-dsDNA, anti-Sm, anti-RNP and antiRo60 autoantibodies. Levels of sMer also correlated with sCD163, a marker of macrophage M2c polarization, and also with SLE disease activity index [66]. Excessive sMer and/or its ligands may compete with cell-bound TAM receptors to block TAM-mediated clearance of apoptotic cells and macrophage signaling. Decreased clearance of apoptotic cells is suggested to be a major pathogenic factor in SLE.

Leukocyte tyrosine kinase (Ltk) is another receptor tyrosine kinase belonging to the insulin receptor family, and is mainly expressed in pre-B cells and neuronal tissues [67]. Ligands for Ltk have not been identified and the physiological role of Ltk remains largely unknown. Most functional analyses of the receptor were carried out with chimeric receptor molecules $[68,69]$. Interestingly, the Ltk gene is closely linked to Tyro-3, one of the TAM family receptor tyrosine kinases [70]. Sequence and functional analyses of the gene revealed that NZB mice have a gain-of-function polymorphism in the Ltk kinase domain near the P85 binding motif YXXM. Human Ltk shows 90\% homology with the mouse Ltk kinase domain and the same Ltk polymorphism was also found in SLE patients with a significantly higher frequency compared with the healthy controls [71].

PDGFs are a family of four cystine-knot-type growth factors required for many aspects of embryogenesis. PDGFs stimulate the proliferation of fibroblasts and vascular smooth muscle cells. PDGFs signal through cell surface PDGF receptor tyrosine kinase (PDGFR), inducing receptor dimerization and initiating various signaling pathways [72]. PDGF plays an important role in the pathogenesis of mesangial proliferative glomerulonephritis. A positive correlation between PDGF- $\beta+$ cells and glomerular cells was reported in kidneys of MRL/lpr mice [73]. The PDGF- $\alpha$ and $-\beta$ mRNA levels increased significantly as nephritis progressed in NZB/NZW mice [74]. Zheng et al. studied PDGF levels in renal biopsy specimens from nine lupus nephritis cases by immunohistochemistry. PDGF mRNA levels were found to be much higher in patients with active lesions in glomeruli, compared with those without active lesions [75].

Inhibitors of PDGFR have been developed recently. Imatinib mesylate (Gleevec, formerly known as STI-571) is a tyrosine kinase inhibitor of BCR-abl that also potently inhibits PDGFR. Two lupus-prone mouse models have undergone treatment studies using imatinib. When given at 5 months, NZBW F1 mice survived significantly longer than vehicle-treated mice. The higher survival rate was associated with limited renal damage and significantly delayed onset of proteinuria [76]. MRL/lpr mice were protected from glomerular proliferation and crescent formation when treated with imatinib, which led to a prolonged lifespan [77]. The effect of imatinib in attenuating renal manifestations in diseased lupusprone mice suggests a potential application of this drug in the treatment of human lupus nephritis. 


\section{Tyrosine kinase \& lipid rafts}

Lipid rafts are enriched in cholesterol and the ganglioside, GM1. The dynamic localization of signaling molecules, including tyrosine kinases Lck, Lyn and Csk within lipid rafts, is thought to be essential for the regulation of T- and B-cell activation. Reduced translocation of tyrosine kinases into lipid rafts has been reported in SLE. CD45 can positively and negatively regulate Lck activity by its proximity to the lipid raft-associated Lck. Csk balances the interaction of CD45 and Lck through PAG, a raft-bound adapter protein, thus regulating Lck activity in lipid rafts [78]. Lck was reported to be depleted from lipid rafts in lupus T cells, and restoration of total Lck by atorvastatin in lupus T cells reverses many of the signaling defects characteristic of SLE T cells [79]. Lyn levels in B-cell lipid raft fractions in SLE patients were significantly reduced compared with that in healthy controls [80]. Flores-Borja et al. studied lipid raft-associated proximal signaling and translocation of CD45 and revealed an association between altered CD45 translocation and reduced Lyn expression [81].

\section{Expert commentary}

A large number of tyrosine kinases serve many functions in cell signaling and homeostasis and are particularly important in the immune system. Their involvement in systemic immunity and inflammation is broadly described in this review (Figure 1). It is apparent that compounds targeted to interfere with signaling functions mediated by tyrosine kinases may be useful in controlling excessive and aberrant T- and B-cell activation in SLE and other autoimmune diseases (Table 1). A role for tyrosine kinases in fibrosis may also lead to interventions in this heretofore-untreatable process shared by many inflammatory and autoimmune diseases. Limits in the development of inhibitors of tyrosine kinases in SLE has been pointed out, including severe side effects, the lack of specificity and the relative low benefit of present drugs. It will be of great value if drugs can be developed with low cellular toxicity and a sufficient but not too strong action to regulate the kinases' overactivities in lupus, yet not to interfere with their activities in normal cells.

The TAM receptor tyrosine kinases present a special opportunity to intervene in disease pathogenesis. Here, these molecules serve to control macrophage and DC activation, and to mediate phagocytosis of apoptotic cells. Enhancement of their activity through ligand binding or via biochemical manipulation of their signaling may be useful in increasing clearance of immunogenic apoptotic debris, and in controlling macrophage polarization [82]. In this regard, genetically enforced increased expression of Mer has recently been shown to be of benefit in collagen-induced arthritis [82]. Blocking the function of the TAM kinases using antibodies or antagonists might also prove useful therapeutically as an approach to immunodeficiency diseases.

\section{Five-year view}

Over the next 5 years, we can expect to see emergence of additional tyrosine kinase inhibitors, and the application of existing inhibitors to animal models of autoimmunity and in clinical trials in human SLE. Approaches to stimulation of TAM receptors in animals can 
be expected as new monoclonals are developed, and promising data may lead to human clinical trials.

\section{Acknowledgments}

The authors were supported by grants from NIAID (U19AI10822726) and NIDDK (1K01DK095067).

\section{References}

Papers of special note have been highlighted as:

- of interest

•• of considerable interest

1. Turner M, Mee PJ, Costello PS, et al. Perinatal lethality and blocked B-cell development in mice lacking the tyrosine kinase Syk. Nature. 1995; 378(6554):298-302. [PubMed: 7477352]

2. Cheng AM, Rowley B, Pao W, et al. Syk tyrosine kinase required for mouse viability and B-cell development. Nature. 1995; 378(6554):303-306. [PubMed: 7477353]

3. Krishnan S, Juang YT, Chowdhury B, et al. Differential expression and molecular associations of Syk in systemic lupus erythematosus T cells. J Immunol. 2008; 181(11):8145-8152. [PubMed: 19018007]

4. Nambiar MP, Fisher CU, Kumar A, et al. Forced expression of the Fc receptor gamma-chain renders human T cells hyperresponsive to TCR/CD3 stimulation. J Immunol. 2003; 170(6):2871-2876. [PubMed: 12626537]

5. Grammatikos AP, Ghosh D, Devlin A, et al. Spleen tyrosine kinase (Syk) regulates systemic lupus erythematosus (SLE) T Cell signaling. PLoS One. 2013; 8(8):e74550. [PubMed: 24013589]

6. Konigsberger S, Prodohl J, Stegner D, et al. Altered BCR signalling quality predisposes to autoimmune disease and a pre-diabetic state. EMBO J. 2012; 31(15):3363-3374. [PubMed: 22728826]

7. Braselmann S, Taylor V, Zhao H, et al. R406, an orally available spleen tyrosine kinase inhibitor blocks fc receptor signaling and reduces immune complex-mediated inflammation. J Pharmacol Exp Ther. 2006; 319(3):998-1008. [PubMed: 16946104]

8. Bahjat FR, Pine PR, Reitsma A, et al. An orally bioavailable spleen tyrosine kinase inhibitor delays disease progression and prolongs survival in murine lupus. Arthritis Rheum. 2008; 58(5):14331444. [PubMed: 18438845] • Significantly increased survival rate associated with improved kidney function in NZB/W F1 mice with long-term R788 treatment.

9. Deng GM, Liu L, Bahjat FR, et al. Suppression of skin and kidney disease by inhibition of spleen tyrosine kinase in lupus-prone mice. Arthritis Rheum. 2010; 62(7):2086-2092. [PubMed: 20222110]

10. Stanczyk J, Ospelt C, Gay S. Is there a future for small molecule drugs in the treatment of rheumatic diseases? Curr Opin Rheumatol. 2008; 20(3):257-262. [PubMed: 18388515]

11. Genovese MC, Kavanaugh A, Weinblatt ME, et al. An oral Syk kinase inhibitor in the treatment of rheumatoid arthritis: a three-month randomized, placebo-controlled, phase II study in patients with active rheumatoid arthritis that did not respond to biologic agents. Arthritis Rheum. 2011; 63(2): 337-345. [PubMed: 21279990]

12. Yang WC, Collette Y, Nunes JA, Olive D. Tec kinases: a family with multiple roles in immunity. Immunity. 2000; 12(4):373-382. [PubMed: 10795735]

13. Mohamed AJ, Yu L, Backesjo CM, et al. Bruton's tyrosine kinase (Btk): function, regulation, and transformation with special emphasis on the PH domain. Immunol Rev. 2009; 228(1):58-73. [PubMed: 19290921]

14. Kil LP, de Bruijn MJ, van Nimwegen M, et al. Btk levels set the threshold for B-cell activation and negative selection of autoreactive B cells in mice. Blood. 2012; 119(16):3744-3756. [PubMed: 22383797] 
15. Halcomb KE, Musuka S, Gutierrez T, et al. Btk regulates localization, in vivo activation, and class switching of anti-DNA B cells. Mol Immunol. 2008; 46(2):233-241. [PubMed: 18849077]

16. Kenny EF, Quinn SR, Doyle SL, et al. Bruton's tyrosine kinase mediates the synergistic signalling between TLR9 and the B cell receptor by regulating calcium and calmodulin. PLoS One. 2013; 8(8):e74103. [PubMed: 23967355]

17. Byrne JC, Ni Gabhann J, Stacey KB, et al. Bruton's tyrosine kinase is required for apoptotic cell uptake via regulating the phosphorylation and localization of calreticulin. J Immunol. 2013; 190(10):5207-5215. [PubMed: 23596312]

18. Amoras AL, Kanegane H, Miyawaki T, Vilela MM. Defective Fc-, CR1- and CR3-mediated monocyte phagocytosis and chemotaxis in common variable immunodeficiency and X-linked agammaglobulinemia patients. J Investig Allergol Clin Immunol. 2003; 13(3):181-188.

19. Vargas L, Hamasy A, Nore BF, Smith CI. Inhibitors of BTK and ITK: state of the new drugs for cancer, autoimmunity and inflammatory diseases. Scand J Immunol. 2013; 78(2):130-139. [PubMed: 23672610]

20. Akinleye A, Chen Y, Mukhi N, et al. Ibrutinib and novel BTK inhibitors in clinical development. J Hematol Oncol. 2013; 6:59. [PubMed: 23958373]

21. Brown JR. Ibrutinib (PCI-32765), the first BTK (Bruton's tyrosine kinase) inhibitor in clinical trials. Curr Hematol Malig Rep. 2013; 8(1):1-6. [PubMed: 23296407]

22. Hutcheson J, Vanarsa K, Bashmakov A, et al. Modulating proximal cell signaling by targeting Btk ameliorates humoral autoimmunity and end-organ disease in murine lupus. Arthritis Res Ther. 2012; 14(6):R243. [PubMed: 23136880] - Ibrutinib treatment alleviated renal damage in B6.sle1.sle3 mice.

23. Mina-Osorio P, LaStant J, Keirstead N, et al. Suppression of glomerulonephritis in lupus-prone NZB $\times$ NZW mice by RN486, a selective inhibitor of Bruton's tyrosine kinase. Arthritis Rheum. 2013; 65(9):2380-2391. [PubMed: 23754328] •• RN486 completely stopped glomerulonephritis progression in NZB/W F1 mice.

24. Graham DSC, Akil M, Vyse TJ. Association of polymorphisms across the tyrosine kinase gene, TYK2 in UK SLE families. Rheumatology (Oxford). 2007; 46(6):927-930. [PubMed: 17384181]

25. Jarvinen TM, Hellquist A, Koskenmies S, et al. Tyrosine kinase 2 and interferon regulatory factor 5 polymorphisms are associated with discoid and subacute cutaneous lupus erythematosus. Exp Dermatol. 2009; 19(2):123-131. [PubMed: 19758313]

26. Sigurdsson S, Nordmark G, Goring HH, et al. Polymorphisms in the tyrosine kinase 2 and interferon regulatory factor 5 genes are associated with systemic lupus erythematosus. Am J Hum Genet. 2005; 76(3):528-537. [PubMed: 15657875]

27. Hellquist A, Jarvinen TM, Koskenmies S, et al. Evidence for genetic association and interaction between the TYK2 and IRF5 genes in systemic lupus erythematosus. J Rheumatol. 2009; 36(8): 1631-1638. [PubMed: 19567624]

28. Suarez-Gestal M, Calaza M, Gonzalez A. Lack of interaction between systemic lupus erythematosus-associated polymorphisms in TYK2 and IRF5. J Rheumatol. 2010; 37(3):676-677. author reply 678. [PubMed: 20197570]

29. Li P, Chang YK, Shek KW, Lau YL. Lack of association of TYK2 gene polymorphisms in Chinese patients with systemic lupus erythematosus. J Rheumatol. 2011; 38(1):177-178. [PubMed: 21196586]

30. Kyogoku C, Morinobu A, Nishimura K, et al. Lack of association between tyrosine kinase 2 (TYK2) gene polymorphisms and susceptibility to SLE in a Japanese population. Mod Rheumatol. 2009; 19(4):401-406. [PubMed: 19440814]

31. Lee YH, Choi SJ, Ji JD, Song GG. Associations between PXK and TYK2 polymorphisms and systemic lupus erythematosus: a meta-analysis. Inflamm Res. 2012; 61(9):949-954. [PubMed: 22592861]

32. Chan VW, Meng F, Soriano P, et al. Characterization of the B lymphocyte populations in Lyndeficient mice and the role of Lyn in signal initiation and down-regulation. Immunity. 1997; 7(1): 69-81. [PubMed: 9252121] 
33. Cornall RJ, Cyster JG, Hibbs ML, et al. Polygenic autoimmune traits: lyn, CD22, and SHP-1 are limiting elements of a biochemical pathway regulating BCR signaling and selection. Immunity. 1998; 8(4):497-508. [PubMed: 9586639]

34. Hibbs ML, Tarlinton DM, Armes J, et al. Multiple defects in the immune system of Lyn-deficient mice, culminating in autoimmune disease. Cell. 1995; 83(2):301-311. [PubMed: 7585947]

35. Nishizumi H, Taniuchi I, Yamanashi Y, et al. Impaired proliferation of peripheral B cells and indication of autoimmune disease in lyn-deficient mice. Immunity. 1995; 3(5):549-560. [PubMed: 7584145]

36. Lamagna C, Scapini P, van Ziffle JA, et al. Hyperactivated MyD88 signaling in dendritic cells, through specific deletion of Lyn kinase, causes severe autoimmunity and inflammation. Proc Natl Acad Sci USA. 2013; 110(35):E3311-E3320. [PubMed: 23940344]

37. Hibbs ML, Harder KW, Armes J, et al. Sustained activation of Lyn tyrosine kinase in vivo leads to autoimmunity. J Exp Med. 2002; 196(12):1593-1604. [PubMed: 12486102]

38. Liossis SN, Solomou EE, Dimopoulos MA, et al. B-cell kinase lyn deficiency in patients with systemic lupus erythematosus. J Investig Med. 2001; 49(2):157-165.

39. Lu R, Vidal GS, Kelly JA, et al. Genetic associations of LYN with systemic lupus erythematosus. Genes Immun. 2009; 10(5):397-403. [PubMed: 19369946]

40. Van Laethem F, Tikhonova AN, Pobezinsky LA, et al. Lck availability during thymic selection determines the recognition specificity of the T cell repertoire. Cell. 2013; 154(6):1326-1341. [PubMed: 24034254]

41. Chuang E, Lee KM, Robbins MD, et al. Regulation of cytotoxic T lymphocyte-associated molecule-4 by Src kinases. J Immunol. 1999; 162(3):1270-1277. [PubMed: 9973379]

42. Jury EC, Kabouridis PS, Abba A, et al. Increased ubiquitination and reduced expression of LCK in T lymphocytes from patients with systemic lupus erythematosus. Arthritis Rheum. 2003; 48(5): 1343-1354. [PubMed: 12746907]

43. Matache C, Onu A, Stefanescu M, et al. Dysregulation of p56lck kinase in patients with systemic lupus erythematosus. Autoimmunity. 2001; 34(1):27-38. [PubMed: 11681490]

44. Salmond RJ, Filby A, Qureshi I, et al. T-cell receptor proximal signaling via the Src-family kinases, Lck and Fyn, influences T-cell activation, differentiation, and tolerance. Immunol Rev. 2009; 228(1):9-22. [PubMed: 19290918]

45. Clements JL, Wolfe J, Cooper SM, Budd RC. Reversal of hyporesponsiveness in lpr CD4-CD8- T cells is achieved by induction of cell cycling and normalization of CD2 and p59fyn expression. Eur J Immunol. 1994; 24(3):558-565. [PubMed: 7510235]

46. Balomenos D, Rumold R, Theofilopoulos AN. The proliferative in vivo activities of lpr doublenegative $\mathrm{T}$ cells and the primary role of p59fyn in their activation and expansion. J Immunol. 1997; 159(5):2265-2273. [PubMed: 9278315]

47. Kozlowska A, Hrycaj P, Lacki JK, Jagodzinski PP. Fyn and CD70 expression in CD4+ T cells from patients with systemic lupus erythematosus. J Rheumatol. 2009; 37(1):53-59. [PubMed: 19955046]

48. Yu CC, Yen TS, Lowell CA, DeFranco AL. Lupus-like kidney disease in mice deficient in the Src family tyrosine kinases Lyn and Fyn. Curr Biol. 2001; 11(1):34-38. [PubMed: 11166177] •• Severe lupus-like disease developed in Lyn/Fyn double knockout mice through distinct mechanisms.

49. Hom G, Graham RR, Modrek B, et al. Association of systemic lupus erythematosus with C8orf13BLK and ITGAM-ITGAX. N Engl J Med. 2008; 358(9):900-909. [PubMed: 18204098]

50. Okada M. Regulation of the SRC family kinases by Csk. Int J Biol Sci. 2012; 8(10):1385-1397. [PubMed: 23139636]

51. Gregersen PK, Lee HS, Batliwalla F, Begovich AB. PTPN22: setting thresholds for autoimmunity. Semin Immunol. 2006; 18(4):214-223. [PubMed: 16731003]

52. Manjarrez-Orduno N, Marasco E, Chung SA, et al. CSK regulatory polymorphism is associated with systemic lupus erythematosus and influences B-cell signaling and activation. Nat Genet. 2012; 44(11):1227-1230. [PubMed: 23042117] 
53. de la Puerta ML, Trinidad AG, Rodriguez Mdel C, et al. The autoimmunity risk variant LYPW620 cooperates with CSK in the regulation of TCR signaling. PLoS One. 2013; 8(1):e54569. [PubMed: 23359562]

54. Lemke G, Rothlin CV. Immunobiology of the TAM receptors. Nat Rev Immunol. 2008; 8(5):327336. [PubMed: 18421305]

55. Rothlin CV, Ghosh S, Zuniga EI, et al. TAM receptors are pleiotropic inhibitors of the innate immune response. Cell. 2007; 131(6):1124-1136. [PubMed: 18083102]

56. Carrera Silva EA, Chan PY, Joannas L, et al. T cell-derived protein S engages TAM receptor signaling in dendritic cells to control the magnitude of the immune response. Immunity. 2013; 39(1):160-170. [PubMed: 23850380]

57. Cohen PL, Caricchio R, Abraham V, et al. Delayed apoptotic cell clearance and lupus-like autoimmunity in mice lacking the c-mer membrane tyrosine kinase. J Exp Med. 2002; 196(1):135140. [PubMed: 12093878]

58. Lu Q, Lemke G. Homeostatic regulation of the immune system by receptor tyrosine kinases of the Tyro 3 family. Science. 2001; 293(5528):306-311. [PubMed: 11452127] • Broad spectrum of autoimmune pathology developed in TAM triple knockout mice.

59. Lu Q, Gore M, Zhang Q, et al. Tyro-3 family receptors are essential regulators of mammalian spermatogenesis. Nature. 1999; 398(6729):723-728. [PubMed: 10227296]

60. Qian Y, Conway KL, Lu X, et al. Autoreactive MZ and B-1 B-cell activation by Faslpr is coincident with an increased frequency of apoptotic lymphocytes and a defect in macrophage clearance. Blood. 2006; 108(3):974-982. [PubMed: 16861350]

61. Cheong HS, Lee SO, Choi CB, et al. MERTK polymorphisms associated with risk of haematological disorders among Korean SLE patients. Rheumatology (Oxford). 2007; 46(2):209214. [PubMed: 16837475]

62. Wu J, Ekman C, Jonsen A, et al. Increased plasma levels of the soluble Mer tyrosine kinase receptor in systemic lupus erythematosus relate to disease activity and nephritis. Arthritis Res Ther. 2011; 13(2):R62. [PubMed: 21496228]

63. Recarte-Pelz P, Tassies D, Espinosa G, et al. Vitamin K-dependent proteins GAS6 and Protein S and TAM receptors in patients of systemic lupus erythematosus: correlation with common genetic variants and disease activity. Arthritis Res Ther. 2013; 15(2):R41. [PubMed: 23497733]

64. Suh CH, Hilliard B, Li S, et al. TAM receptor ligands in lupus: protein S but not Gas6 levels reflect disease activity in systemic lupus erythematosus. Arthritis Res Ther. 2010; 12(4):R146. [PubMed: 20637106]

65. Hilliard BA. Increased expression of Mer tyrosine kinase in circulating dendritic cells and monocytes of lupus patients: correlations with plasma interferon activity and steroid therapy. Arthritis Res Ther. 2014 In press.

66. Zizzo G, Guerrieri J, Dittman LM, et al. Circulating levels of soluble MER in lupus reflect M2c activation of monocytes/ macrophages, autoantibody specificities and disease activity. Arthritis Res Ther. 2013; 15(6):R212. [PubMed: 24325951]

67. Krolewski JJ, Dalla-Favera R. The ltk gene encodes a novel receptor-type protein tyrosine kinase. EMBO J. 1991; 10(10):2911-2919. [PubMed: 1655406]

68. Yamada S, Nomura T, Takano K, et al. Expression of a chimeric CSF1R-LTK mediates liganddependent neurite outgrowth. Neuroreport. 2008; 19(17):1733-1738. [PubMed: 18849880]

69. Ueno H, Hirano N, Kozutsumi H, et al. An epidermal growth factor receptor-leukocyte tyrosine kinase chimeric receptor generates ligand-dependent growth signals through the Ras signaling pathway. J Biol Chem. 1995; 270(34):20135-20142. [PubMed: 7650032]

70. Liao X, Zhou R, Gilbert DJ, et al. Receptor tyrosine kinase gene Tyro3 maps to mouse chromosome 2, closely linked to Ltk. Mamm Genome. 1996; 7(5):395-396. [PubMed: 8661736]

71. Li N, Nakamura K, Jiang Y, et al. Gain-of-function polymorphism in mouse and human Ltk: implications for the pathogenesis of systemic lupus erythematosus. Hum Mol Genet. 2004; 13(2): 171-179. [PubMed: 14695357]

72. Chen PH, Chen X, He X. Platelet-derived growth factors and their receptors: structural and functional perspectives. Biochim Biophys Acta. 2013; 1834(10):2176-2186. [PubMed: 23137658] 
73. Entani C, Izumino K, Takata M, et al. Expression of platelet-derived growth factor in lupus nephritis in MRL/MpJ-1pr/1pr mice. Nephron. 1997; 77(1):100-104. [PubMed: 9380223]

74. Nakamura T, Ebihara I, Nagaoka I, et al. Renal platelet-derived growth factor gene expression in NZB/W F1 mice with lupus and ddY mice with IgA nephropathy. Clin Immunol Immunopathol. 1992; 63(2):173-181. [PubMed: 1611719]

75. Zheng F, Liu Z, Zhou H. [Impact of platelet derived growth factor in the glomeruli of active lupus nephritis]. Zhonghua Nei Ke Za Zhi. 1996; 35(9):601-605. [PubMed: 9592354]

76. Zoja C, Corna D, Rottoli D, et al. Imatinib ameliorates renal disease and survival in murine lupus autoimmune disease. Kidney Int. 2006; 70(1):97-103. [PubMed: 16688113]

77. Sadanaga A, Nakashima H, Masutani K, et al. Amelioration of autoimmune nephritis by imatinib in MRL/lpr mice. Arthritis Rheum. 2005; 52(12):3987-3996. [PubMed: 16320345] • Imatinib treatment in MRL/lpr mice resulted in higher survival rate and limited renal damage.

78. Kabouridis PS. Selective interaction of LAT (linker of activated T cells) with the open-active form of Lck in lipid rafts reveals a new mechanism for the regulation of Lck in T cells. Biochem J. 2003; 371(Pt 3):907-915. [PubMed: 12570875]

79. Jury EC, Isenberg DA, Mauri C, Ehrenstein MR. Atorvastatin restores Lck expression and lipid raft-associated signaling in $\mathrm{T}$ cells from patients with systemic lupus erythematosus. J Immunol. 2006; 177(10):7416-7422. [PubMed: 17082661]

80. Flores-Borja F, Kabouridis PS, Jury EC, et al. Decreased Lyn expression and translocation to lipid raft signaling domains in B lymphocytes from patients with systemic lupus erythematosus. Arthritis Rheum. 2005; 52(12):3955-3965. [PubMed: 16320343]

81. Flores-Borja F, Kabouridis PS, Jury EC, et al. Altered lipid raft-associated proximal signaling and translocation of CD45 tyrosine phosphatase in B lymphocytes from patients with systemic lupus erythematosus. Arthritis Rheum. 2007; 56(1):291-302. [PubMed: 17195233]

82. van den Brand BT, Abdollahi-Roodsaz S, Vermeij EA, et al. Therapeutic efficacy of Tyro3, Axl, and Mer tyrosine kinase agonists in collagen-induced arthritis. Arthritis Rheum. 2012; 65(3):671680. [PubMed: 23203851] 


\section{Key issues}

- Systemic lupus erythematosus (SLE) is an autoimmune disease of unknown cause characterized by production of autoantibodies, involving multiple organs. Clinical manifestations of SLE are diverse.

- Loss of self-tolerance to self-antigen is the key issue, while genetic, epigenetic and environmental factors contribute to the development and clinical manifestations of the disease.

- The need for new therapies reflects the complexity and difficulty of this disease.

- Tyrosine kinases are important in many aspects of cell signal transduction involving survival, activation and differentiation.

- Efforts to block tyrosine kinase activity seem to provide clinical benefits in patients with rheumatoid arthritis and allergic disease.

- Tyrosine kinase inhibitors have attracted considerable interest for further development in clinical trials in SLE patients. 


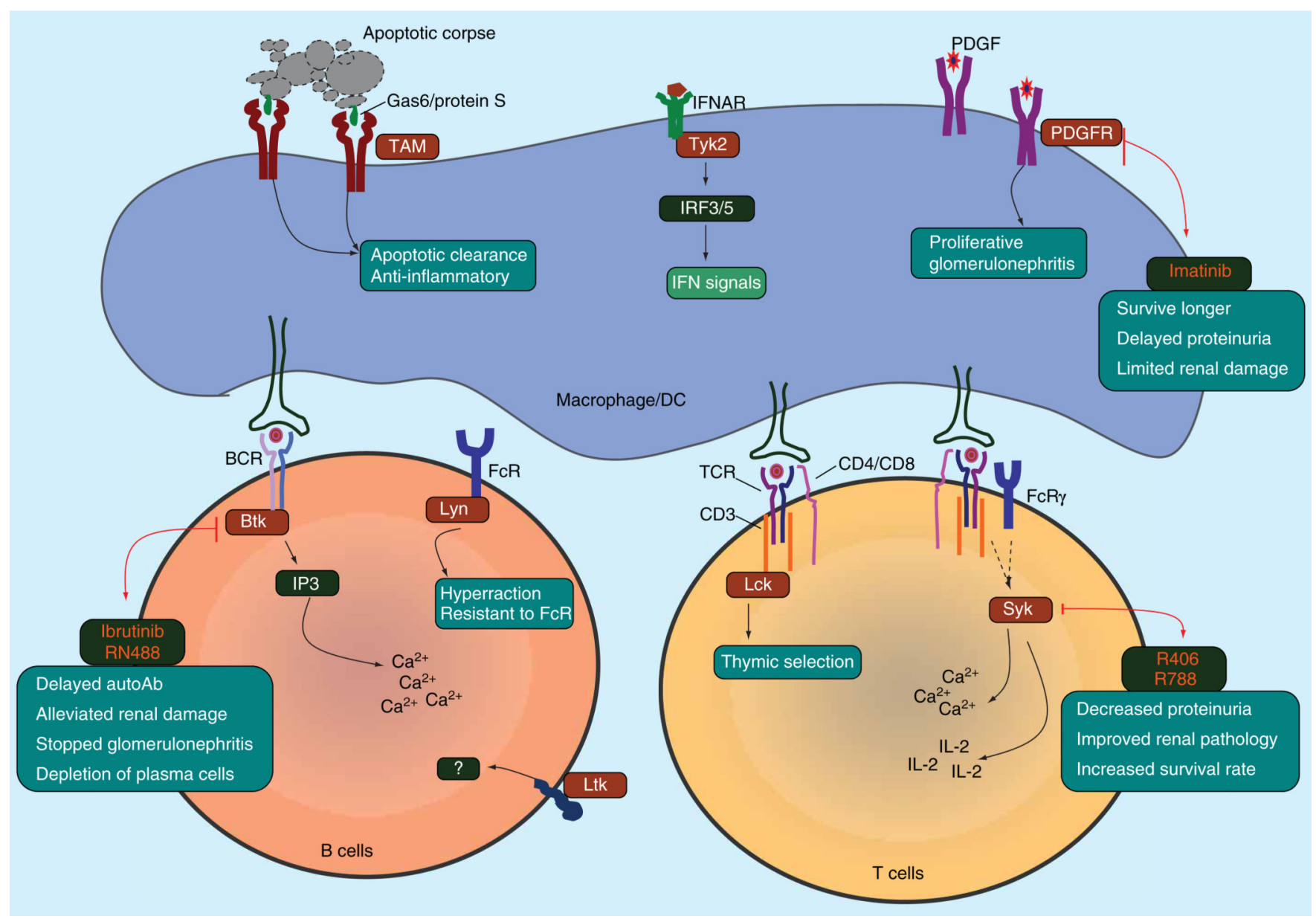

Figure 1. Mechanistic and therapeutic roles of tyrosine kinases in systemic lupus erythematosus Abnormal tyrosine kinase-mediated signal pathways in systemic lupus erythematosus immune cells. All tyrosine kinases are shown in brown. All inhibitors are shown in red. IFN: Interferon; PDGFR: PDGF receptor. 
Table 1

Tyrosine kinases and inhibitors involved in systemic lupus erythematosus.

\begin{tabular}{|c|c|c|c|c|}
\hline Target & Function & Inhibitors & Association with SLE & Mouse study/clinical trial \\
\hline Syk & $\begin{array}{l}\text { TCR and BCR } \\
\text { signaling }\end{array}$ & R788 (fostamatinib), R406 & $\begin{array}{l}\text { Higher Syk expression and activity } \\
\text { in SLE T cells }\end{array}$ & $\begin{array}{l}\text { R788 shows long-term benefit in } \\
\text { lupus mice, but no efficacy in RA } \\
\text { clinical trials }\end{array}$ \\
\hline Btk & B-cell activation & PCI-32765 (ibrutinib), RN486 & $\begin{array}{l}\text { Overexpression of Btk in B cells } \\
\text { leads to hyperresponsiveness to } \\
\text { BCR }\end{array}$ & $\begin{array}{l}\text { SLE-like autoimmunity develops in } \\
\text { Btk transgenic mice; ibrutinib } \\
\text { dampens humoral autoimmunity in } \\
\text { B6.sle1 mice; RN486 stops the } \\
\text { progression of glomerulonephritis in } \\
\text { NZBW mice }\end{array}$ \\
\hline Tyk2 & IFN-I signaling & n.a. & $\begin{array}{l}\text { Polymorphism associated with } \\
\text { SLE and DLE }\end{array}$ & n.a \\
\hline Lyn & $\begin{array}{l}\text { Negative regulator } \\
\text { of B-cell activation }\end{array}$ & n.a. & $\begin{array}{l}\text { Lower Lyn in resting B cells from } \\
\text { SLE patients. Lyn rs6983130 is } \\
\text { associated with SLE }\end{array}$ & $\begin{array}{l}\text { Both } \mathrm{Lyn}^{-/-} \text {and Lyn }{ }^{\text {up/up }} \text { mice } \\
\text { develop pathologic features of SLE }\end{array}$ \\
\hline Lck & $\begin{array}{l}\text { T-cell development } \\
\text { and activation }\end{array}$ & n.a. & $\begin{array}{l}\text { Reduced Lck in peripheral T cells } \\
\text { from SLE patients }\end{array}$ & n.a. \\
\hline Fyn & $\begin{array}{l}\text { TCR proximal signal } \\
\text { transduction }\end{array}$ & n.a. & $\begin{array}{l}\text { Higher mRNA levels in SLE CD4 }{ }^{+} \\
\text {T cells }\end{array}$ & $\begin{array}{l}\text { Fyn deficiency predisposes the } \\
\text { glomeruli to damage }\end{array}$ \\
\hline Blk & B-cell signaling & n.a. & $\begin{array}{l}\text { Reduced Blk linked with } \\
\text { decreased risk of SLE }\end{array}$ & n.a. \\
\hline Csk & $\begin{array}{l}\text { Negative regulator } \\
\text { of Src family }\end{array}$ & n.a. & $\begin{array}{l}\text { Csk mutation associated with } \\
\text { increased mature B-cell activation } \\
\text { and higher IgM in SLE }\end{array}$ & $\begin{array}{l}\mathrm{Csk}^{-/-} \text {embryos die at neurulation } \\
\text { stages }\end{array}$ \\
\hline TAM & $\begin{array}{l}\text { Apoptotic cell } \\
\text { clearance, } \\
\text { macrophage/DC } \\
\text { regulation }\end{array}$ & n.a. & $\begin{array}{l}\text { Increased soluble TAM receptors } \\
\text { in the plasma of SLE patients }\end{array}$ & $\begin{array}{l}\mathrm{TAM}^{-/-} \text {mice develop severe } \\
\text { autoimmune disorder }\end{array}$ \\
\hline Ltk & $\begin{array}{l}\text { TCR and BCR } \\
\text { signaling }\end{array}$ & n.a. & $\begin{array}{l}\text { Higher frequency of Ltk gain-of- } \\
\text { function polymorphism in SLE } \\
\text { patients }\end{array}$ & $\begin{array}{l}\text { Ltk gain-of-function polymorphism } \\
\text { in NZB mice }\end{array}$ \\
\hline
\end{tabular}

BCR: B-cell receptor; DLE: Discoid lupus erythematosus; n.a.: Not applicable; NZBW: (NZB $\times$ NZW) F1; RA: Rheumatoid arthritis; SLE: Systemic lupus erythematosus; TCR: T-cell receptor. 